\title{
How to Use Q Methodology in Engineering Education Research
}

\section{Ms. Renee Desing, The Ohio State University}

Renee Desing is currently a PhD Candidate at the Ohio State University in the Department of Engineering Education. Ms. Desing holds a B.S. in Industrial Engineering from the Georgia Institute of Technology and a M.S. in Industrial Engineering and Operations Research from the Pennsylvania State University. Most recently, Ms. Desing worked as a managing consultant for IBM Public Sector Advanced Analytics.

\section{Dr. Rachel Louis Kajfez, The Ohio State University}

Dr. Rachel Louis Kajfez is an Assistant Professor in the Department of Engineering Education at The Ohio State University. She earned her B.S. and M.S. degrees in Civil Engineering from Ohio State and earned her Ph.D. in Engineering Education from Virginia Tech. Her research interests focus on the intersection between motivation and identity of undergraduate and graduate students, first-year engineering programs, mixed methods research, and innovative approaches to teaching. 


\title{
How to Use Q Methodology in Engineering Education Research
}

\begin{abstract}
Graduate and undergraduate student researchers are continually learning and performing research methodologies as part of research assistantships or for independent theses and dissertations. Particularly in engineering education research, it is important for student researchers to have working knowledge of and practice using a variety of methodologies. To support the growth of student researchers, this "tricks of the trade" paper explains Q methodology, a mixed methods research methodology, and how it can be utilized in engineering education.

Q methodology is a social science research methodology focused on systematically studying subjectivity utilizing both qualitative and quantitative research techniques. The methodology is used to study how people think about a topic (e.g., their viewpoints, perspectives, or beliefs), resulting in a set of subjective viewpoints which represent the way of thinking regarding a topic. As an inherently convergent mixed methods design, $Q$ methodology explains the quantitative results of a factor analysis using the qualitative findings from interviews. While $\mathrm{Q}$ methodology has had limited use in engineering education research to-date, it has a larger presence in education and educational psychology research more broadly.

This paper details the history of Q methodology, when it is appropriate to use it as a research design within engineering education research, the components of the methodology, how to execute a Q methodology study, and how to analyze and interpret the results. A detailed example from a dissertation is provided for how $\mathrm{Q}$ methodology is currently being used to study the experiences of early career women engineers when they encounter gender-based challenges in the workplace. Ultimately, this paper demonstrates and promotes the strengths of Q methodology within engineering education research and provides student researchers actionable steps and knowledge to advance their research skills.
\end{abstract}

\section{Introduction}

For engineering education to continue to grow and evolve, it is important for researchers to continue to learn and implement new research methodologies pushing past the typical modes of data collection and analysis. Learning new methodologies can help researchers answer new questions and extend our understanding of education. New methodologies afford researchers new tools and techniques which lead to new answers and insights.

Methodologies are chosen by the researcher to best answer their research question, hypothesis, or purpose of the study [1]. A mixed methods research methodology that a researcher may select is Q methodology. Q methodology is a social science research methodology focused on systematically studying subjectivity utilizing both qualitative and quantitative research techniques [2]-[6]. While Q methodology has had limited use in engineering education research, it has been used in studies regarding the career paths of engineering education doctoral graduates [7], competencies for nanotechnology [8] and IT [9], curriculum design for information systems [10], construction engineering technology program assessment [11], and undergraduate 
engineering students' out-of-class activities [12]. However, Q methodology has a longer and larger presence in education research (337 studies were found in an ERIC database search from 1970 to 2003 [13]), including studies about higher education [14]-[16], undergraduate women's perspectives on mathematics [17], and science education [18]-[20]. Therefore, Q methodology's applications to engineering education research make it a viable selection for researchers, assuming the methodology aligns with the research question.

\section{Purpose}

Because Q methodology has limited used in engineering education research, graduate and undergraduate student researchers may not know what it is or how to use it appropriately for their research. Therefore, the purpose of this paper is to define Q methodology, explain how to execute a Q methodology study, and provide an example of how Q methodology is being used in a current engineering education graduate student's dissertation research study.

\section{What is Q Methodology?}

Q methodology was developed by William Stephenson [3], a physics and psychology researcher, and expanded over the course of his career [21], [22]. The social science research methodology is used to study how people think about a topic (e.g., their viewpoints, perspectives, attitudes, beliefs, and other similar statements) [2], [4]. Q methodology consists of the following components:

- Q Concourse: A set of all statements regarding a topic that may be collected from interviews, publications, or other sources, and may include content such as photographs, advertisements, posters, and music in addition to discourse [23], [24];

- Q-Set or Q Sample: A representative subset of the Q Concourse, typically 30-60 statements [23];

- P-Set: A structured, non-random set of participants [25], [26]; and

- Q-Sort: A rank-ordered distribution of the statements in the Q-Set by each of the participants in the P-Set [2].

The sorting process used to collect the Q-Sorts is a defining characteristic of Q methodology and differs from other data collection methods. During a Q-Sort interview, the participant is asked to sort the statements in the Q-Set into a pre-determined, quasinormal distribution shape along a scale, such as how strongly they agree or disagree with the statement [2], [27]. An example of this shape is shown in Figure 1, where one statement is placed in each box while sorting. This process requires the participants to consider the statements relative to

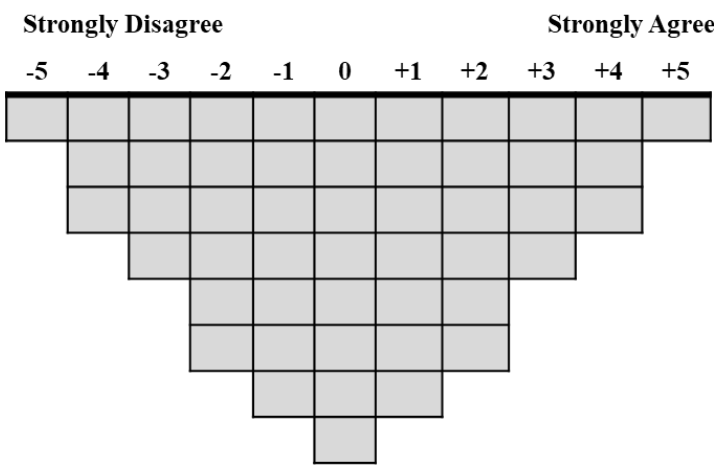

Figure 1: Example Q-Sort Distribution one another, rather than selecting an absolute rating from -5 to +5 for each statement, as in a 
Likert-type survey [25]. By sorting the statements relatively, the participants' viewpoints on the topic are more clearly defined.

The results of a Q methodology study are a set of subjective viewpoints, or factors, which represent the various ways people think about a specific topic or domain as well as explanations for those viewpoints [2]. A factor analysis is used to define these factors by assessing the correlations between participants across the statements in the Q-Set, thereby considering the participants to be the variables rather than the statements in the Q-Set [2], [25]. In other words, the participants are the items being grouped into factors based on how similar they ranked the statements by comparing their Q-Sorts as a whole. This differs from other analyses, such as R factor analysis or cluster analysis, which analyze correlations between the statements [25].

Q methodology is inherently a mixed methods research methodology in both its data collection and analysis processes. Q methodology combines the strengths of qualitative data collection processes to gather participants' viewpoints with the complexity of the data analysis of the quantitative data in order to effectively determine the results. It elicits quantitative data in the form of scores based on the placement of statements in the Q-Sort and a subsequent factor analysis, and qualitative data in the form of interview notes or transcripts and coding analysis. Additionally, the qualitative findings are used to interpret and enhance the quantitative results, thereby mixing the data results. Other methodologies used in engineering education research, such as case study, ethnography, grounded theory, phenomenography, action research discourse analysis, and narrative analysis, focus on using qualitative methods [28]. Q methodology is unique from these methododologies because it integrates quantitative as well as qualitative methods. Being a mixed methods research methodology is a key benefit of Q methodology.

However, there has been much discussion among scholars about the generalizability of Q methodology. Brouwer [29] and Thomas and Baas [30] both address this debate in the same issues of Operant Subjectivity, an international journal dedicated to Q methodology. Brouwer [29] compares the validity of Q methodology with $\mathrm{R}$ method and Thomas and Baas [30] discuss generalizability in terms of either statistical inference and subjective inference, where $\mathrm{Q}$ methodology is concerned with the latter. The goal is to define the shared viewpoints [27], for which only five or six persons are needed to define a factor and produce reliable factor scores [25]. Therefore, in Q methodology, the factors represent generalizations about how people with the same viewpoint think about a topic [25].

\section{How to Conduct a Q Methodology Study}

A Q methodology study consists of five steps: (1) determining the Q Concourse, (2) developing the Q-Set, (3) selecting the P-Set, (4) conducting the Q-Sorts, and (5) analyzing and interpreting the data [26]. These steps are detailed below, with an emphasis on the data collection processes in Steps 1-4, along with an example of how each step was conducted for a current engineering education research study. Best practices are discussed, and call-out boxes highlight important tips ("tricks of the trade") that were learned while employing the methodology in the example 
study, thereby contributing to the promotion and use of Q methodology in engineering education research.

The example study explored the variety of gender-based challenges that early career women engineering professionals experience in the workplace, how these women use counterfactual thinking (defined as thoughts about what might have been or alternatives to reality [31]) to overcome these challenges, and the impact of counterfactual thinking on their career motivation [32]. Q methodology's ability to systematically study subjectivity [23], by combining a qualitative data collection processes with quantitative data analysis, made it a well-aligned methodology to understand the impact of counterfactual thinking on early career women engineers' career motivation as based on their individual experiences.

\section{Step 1: Determining the $Q$ Concourse}

The Q Concourse in Q methodology is based on concourse theory where "the flow of communicability surrounding any topic is referred to as a concourse" [2, p. 94]. A concourse is defined as a universe of statements which exists for any situation or context when viewed subjectively as both conversational and informational statements [24]. Simply, it is the collection of all possible statements about a topic [26], where the number of items is infinite [4]. These statements are not limited to words and may include paintings, photographs, cartoons, or music selections [2]. However, the focus of this study was a verbal concourse.

A verbal concourse may be obtained through means such as interviewing or observing participants, scientific literature, or popular literature such as newspapers [26]. Selecting which method or combination of methods to use to determine the Q Concourse will depend on the purpose and topic of the research study. For example, Anderson [33], who used Q methodology to study work environments of female executives in biotechnology, utilized open-ended webbased interview questions to directly use the participants' responses to develop the Q Concourse. Chang [9], who studied IT competencies for curricular development, combined a literature analysis with interviews with experts in the IT field to form a Q Concourse containing 101 statements. Godor [34], who studied master's students' approaches to studying, considered the 52 items from a validated instrument to be the Q Concourse due to its long history of use. These examples in engineering and education research demonstrate the variety of methods that may be used determine the Q Concourse.

Example Study. In the example study, the Q

Concourse was developed using an extensive literature review focused on three topics: counterfactual thinking, career motivation, and gender-based challenges. The types of literature that were searched and reviewed for statements included validated instruments, such as the Counterfactual Thinking for Negative Events Scale [35] and the Career Motivation Scale [36], and models and theories, such as Career Motivation Theory [32]. Another source for the

\section{Tip \#1}

Keep a detailed (e.g., Excel) database to organize the $\mathrm{Q}$

Concourse. Be sure to track the statements and their sources. 
statements were quotes that were used as results in qualitative research studies. For example, the quote "For me, engineering is more, kind of something that I enjoy, but it's a means to an end, and a way to be able to do other things in life" [37] was included as a statement in the Q Concourse. An Excel database was used to organize the results of the literature search and the Q Concourse. On one tab, information for each source was recorded, including the author and title, description of the article or source, which of the three main topics it covers, and the number of statements from the article that were included in the Q Concourse. The statements were added to the Q Concourse on a separate tab in the Excel file and the following items were tracked: an overall statement identification number, an identification number by source, its main topic, and its sub-topic. Table 1 depicts this structure as a recommended Q Concourse template with example statements.

Table 1: Q Concourse Template with Example

\begin{tabular}{|c|c|c|c|c|c|}
\hline ID & Source ID & Statement & Topic & Sub-Topic & Source \\
\hline 1 & 1 & $\begin{array}{l}\text { I have a specific plan } \\
\text { for achieving my } \\
\text { career goal. }\end{array}$ & $\begin{array}{l}\text { Career } \\
\text { Motivation }\end{array}$ & Career Insight & $\begin{array}{l}\text { Day \& } \\
\text { Allen } \\
(2003)[36]\end{array}$ \\
\hline 2 & 2 & $\begin{array}{l}\text { I welcome job and } \\
\text { organizational } \\
\text { changes. }\end{array}$ & $\begin{array}{l}\text { Career } \\
\text { Motivation }\end{array}$ & $\begin{array}{l}\text { Career } \\
\text { Resilience }\end{array}$ & $\begin{array}{l}\text { Day \& } \\
\text { Allen } \\
(2003)[36]\end{array}$ \\
\hline 3 & 1 & $\begin{array}{l}\text { I have experienced } \\
\text { disrespect, rudeness, } \\
\text { or condescension } \\
\text { from my male } \\
\text { colleagues. }\end{array}$ & $\begin{array}{l}\text { Gender-based } \\
\text { Challenge }\end{array}$ & $\begin{array}{l}\text { Workplace } \\
\text { Hostility }\end{array}$ & $\begin{array}{l}\text { Fouad et al. } \\
\text { (2016) [38] }\end{array}$ \\
\hline$\ldots$ & $\ldots$ & $\ldots$ & $\ldots$ & $\ldots$ & $\ldots$ \\
\hline
\end{tabular}

This organization was used to analyze any gaps in the topics or sub-topics for which further literature searching may be needed to fill the gaps. Once it was determined that no new statements were found in further literature review and all gaps were filled, the Q Concourse was considered saturated. The final Q Concourse contained 353 statements across the three main topics.

\section{Step 2: Developing the $Q$-Set}

Once the Q Concourse is finalized, the Q-Set must be selected. A sample of 30 to 60 statements is typical [23] because the number of statements is not only manageable for the participants during the sorting process but also "broadly representative" of the topics in the Q Concourse [2], [25], [27]. While it is recommended that an equal or balanced number of statements for each topic being studied is included in the Q-Set [2], it is understood that the selection of statements is "more an art than a science" [25, p. 186].

Therefore, the process for sampling statements from the Q Concourse to create the Q-Set varies. For example, Anderson [33] identified seven areas and selected approximately an equal number 
of statements from each area while ensuring that the majority of opinions were represented without being repetitive, resulting in 43 statements in the Q-Set. Another study by Liu, Yueh, Chen, and Sheen [8] to identify nanotechnology competencies for engineering students, used an iterative process to select their Q-Set. To start, the Q Concourse of 410 statements was administered as a Likert-survey to two university professors and the 120 statements which were rated highly were selected for their initial Q-Set. The initial Q-Set was then piloted with two post-doc researchers using the Q-Sort process and a follow-up interview to ask about the relevance of the statements. Using the results of these pilot interviews, the researchers narrowed their final Q-Set down to 47 statements.

Example Study. The example study followed the recommendations for selecting a balanced Q-Set as well as the pilot process by Liu, Yueh, Chen, and Sheen [8] to develop the QSet. To begin the analysis process, the statements in the Q Concourse were refined and smoothed into the Q-Statement structure. For example, the statement "Having autonomy to develop new ideas" was refined as "I enjoy having autonomy to develop new ideas". Next, duplicate statements were removes. Duplicates occurred, for example, if multiple studies used the same instrument. Other statements that were similar were combined and smoothed into one statement. For example, the following statements cover a similar topic: "Pursuing and maintaining qualifications specific to my industry", "Pursuing and maintaining qualifications specific to my company", "Gaining training \& development that prepares me for my current job", and "Developing skills and knowledge that are valued by my company". They were combined and smoothed into the final statement, "My company provides opportunities for me to pursue and maintain qualifications, skills, and knowledge for my industry, company, and/or role".

Next, to ensure a representative and balanced number of statements for each of the three main topics (counterfactual thinking, career motivation, and gender-based challenges), the statements for each topic were analyzed separately. If statements were related to one another, the statements were either merged into one or just one statement was selected. For example, the final statement of "I have experienced verbal remarks made by male colleagues, such as crude jokes, being called "sweetheart", disrespectful, rude, or condescending statements, etc." was derived from two similar statements: "I have been called names such as 'sweetheart' or 'girl' by my male colleagues" and "I have experienced verbal remarks made by male colleagues, such as crude jokes, being called "too pretty to be an engineer", etc.". This process continued iteratively until there were 17 counterfactual thinking statements, 23 career motivation statements, and 20 gender-based challenges statements to represent the Q Concourse. Therefore, the initial Q-Set contained 60 statements.

Once the initial Q-Set was determined, it was piloted using an iterative Q-Sort interview process. Three pilot interviews were conducted, during which the participants sorted the Q-Set and were asked follow-up questions regarding the clarity and relevance of the statements. After each pilot interview, the Q-Set was updated prior to piloting it with the next participant. During the first pilot interview, the participant pointed out that one of the

\section{Tip \#2}

Pilot the Q-Set iteratively before finalizing the statements. 
statements was duplicated on two cards and the cards did not include one of the initial statements from the Q-Set. The Q-Set was subsequently updated to remove the duplicate and include the statement that should have been on the card, keeping the Q-Set at the initial 60 statements. During the discussion portion of the second interview, the participant mentioned a gender-based challenge that was not covered by any of the statements. Therefore, a statement was formulated and added to both the Q Concourse and the updated Q-Set, increasing the number of statements from 60 to 61 . No changes were made after the third pilot interview, resulting in 61 statements in the final Q-Set.

\section{Step 3: Selecting the P-Set}

Selecting the P-Set may occur simultaneously as the development of the Q Concourse and Q-Set. It is important to have enough participants that are expected to represent viewpoints or define a factor [25]. It is recommended that there are four or five participants per anticipated factor, which is usually two to four and rarely more than six [26]. It is also recommended that the size of the P-Set is smaller than the number of statements in the Q-Set [39]. If there are enough participants to define a factor [25] and a sufficient number of factors are defined [26], then the factors will be interpreted as the generalizations about the viewpoints of the participants women who think similarly about the topic [25].

Different techniques have been used to select the P-Set depending on the needs of the study, although discussion on the selection of participants is limited in the publications. Some studies will select participants based on their willingness to participate (e.g., [33]), convenience based on program enrollment (e.g., [34]), or casting a wider net than recommended, such as Chang [9] who stated they received 236 responses to his Q-Sort survey. However, others followed the recommended process and selected participants based on their representativeness of the anticipated viewpoints (e.g., [8]).

Example Study. As the variation in viewpoints is dependent on participant sampling [40], a stratified purposeful sampling procedure [41]-[43]

was used for selecting participants. Purposive sampling is a mixed methods sampling strategy that is used to ensure that a variety of participants based on preselected characteristics are included [41]. To garner interest in the study, a survey was used for potential participants to indicate their interest in participating and provide demographic information about their role and company. Those that responded were divided into sub-groups based on their characteristics (both

\section{Tip \#3}

Use stratified purposeful sampling to form the PSet, rather than a random or convenience sample. individual and company characteristics) and a purposeful sample was selected from each sub-group [43]. This resulted in 20 participants in the P-Set to represent the variety of viewpoints and experiences. 


\section{Step 4: Conducting the Q-Sort}

Once the Q-Set and P-Set are selected, the Q-Sort interviews are performed. First, the materials for the Q-sort interviews need to be prepared. This includes creating the sorting cards, one for each of the statements, as well as the sorting distribution board. This board is arranged as a quasi-normal distribution, where the number of columns and the number of Q statements allotted per column are based on the number of Q statements in the Q-Set as well as how strongly the participants are expected to agree or disagree with the statements. For example, if participants are expected to be more strongly opinionated, then a flatter shape is recommended [25]. While the actual shape of the distribution will not impact the factors that emerge from the Q-Sorts, the distribution board provides a structure for the participants during the rank-order process [2], [25], [27]. The distribution range will depend on the number of statements in the Q-Set. It is recommended that Q-Sets with less than 40 statements use a range of -4 to +4 , Q-Sets with 40 to 60 statements use a range of -5 to +5 , and Q-Sets with more than 60 statements use a range of -6 to +6 or greater [25], [27]. Figure 1 provides an example of a distribution range from -5 to +5 with 50 statements.

Prior to collecting the Q-Sorts, a key decision to make is whether the Q-Sorts will be performed in-person or online. While it is recommended to perform the Q-Sort interviews in-person so that low-quality sorts do not impact the analysis [44], online software is available [45], including a new platform, Q Method Software [46], which allows researchers to increase the number of participants and reduce time and cost to conduct the Q-Sorts.

When conducting the Q-Sort interviews in person, the interviews will last for approximately 60 to 90 minutes, which aligns with Q methodology studies that ranged from sorting 38 statements in 45 minutes [15] to sorting 140 statements in 2 hours [47]. This hour includes both the QSorting process as well as the follow-up interview. During the Q-Sort process, the participants will be provided the cards which contain the statements from the Q-Set and are instructed to sort the statements onto the distribution board relative to one another based on how strongly they agree or disagree with the statements [2]. The participants may use any technique to read through and sort the cards, but it is recommended to instruct them to create three piles: one for the statements with which they agree, one for the statements with which they disagree, and one for the statements for which they are neutral. Next, they will take one pile at a time and rank-order the statements within that pile by placing them onto the sorting board in the designated spaces. This sorting process is inherently subjective [4], [22] and the completed distribution board is considered to be the Q-Sort for that participant and represents their viewpoint on the Q-Set [2].

Immediately following the sorting process, it is recommended to conduct an interview to discuss the participant's rationale for their sorting, particularly those at the far ends of the distribution, to understand their experiences and provide context to their Q-Sort [2], [48]. These interviews will be unstructured or semi-structured because each participant's sort will be different. Because the follow-up interview will be based on their sort, it is important to pay attention to the placement of statements as the participant is completing the Q-Sort. 
If performing the Q-Sort online, the researcher will need to determine whether to contact the participants for follow-up interviews in the future or to not perform follow-up interviews. While the immediacy of the interview is lost, it provides the researcher time to review the Q-Sort and prepare for the interview, rather than constructing the interview questions in real-time.

Example Study. The example study followed the recommendations above to conduct in-person Q-Sort interviews. Since all participants were unfamiliar with the QSort process, the interview started with a quick activity where the participants sorted 9 breakfast food statements onto a mini Q-Sort board. This was successful in increasing the participants understanding of the sorting process and highlighting that there was no right or wrong answer. It was also important to explain that the sorting process is relative; whether they strongly disliked pancakes, it meant that they disliked it more than all the other breakfast food cards, and therefore should place it in the strongly dislike column. This activity may also reduce the time the participants need to complete the full Q-Sort if they already understand the process.

For the Q-Sort with the Q-Set statements, two researchers conducted the interview. One led the interview and one took notes of the Q-Sort process and follow-up interview responses. To start the process, a poster with the distribution shape was placed on the table, which was effective in guiding the participants through the process. While the researchers recommended the participants start by creating three piles, each participant performed the sorting process differently: a few created three piles, some created 5-7 piles, others spread all the cards out, and others placed the cards immediately in a cell on the board after reading it. Because the researchers did not force the participants to stick to the shape exactly, it was interesting to note that about half stuck to the shape and half did not, creating skewed distributions.

\section{Tip \#5}

Provide the participants a sorting board, such as a poster print-out, to guide the participants and allow them to sort directly on the board.

During the follow-up interview, the general question asked was "why did you place this here?", and started with the strongly agree and strongly disagree ends of the board, ending with the neutral statements in the middle. If statements were related to one another, the researchers noted this during the sorting process and jumped across the board to discuss the related statements, often making connections between their placements on the board. There were particular statements that the researchers made sure were specifically discussed in each interviewer. However, the flow of the interview followed the participants' unique Q-Sorts and their responses.

The times to complete each portion of the interview were recorded and analyzed. The results of this analysis are displayed in Table 2. The total interview time includes the introduction, practice 
breakfast food sort, full Q-Sort, follow-up interview, and any concluding statements or questions from the participants. The Q-Sort and follow-up interview times are a subset of the total time. These times aligned with the expected times for the interviews; however, the mean Q-Sorting time of 18 minutes, 51 seconds was shorter than expected.

Table 2: Interview Time Analysis

\begin{tabular}{llll}
\hline Statistic & $\begin{array}{l}\text { Q-Sort Time } \\
\text { (hh:mm:ss) }\end{array}$ & $\begin{array}{l}\text { Follow-up Interview } \\
\text { Time (hh:mm:ss) }\end{array}$ & $\begin{array}{l}\text { Total Interview } \\
\text { Time (hh:mm:ss) }\end{array}$ \\
\hline Min & $00: 08: 29$ & $00: 32: 10$ & $00: 53: 28$ \\
Mean & $00: 18: 51$ & $00: 47: 00$ & $01: 16: 47$ \\
Max & $00: 32: 11$ & $01: 03: 24$ & $01: 30: 12$ \\
\hline
\end{tabular}

Step 5: Analyzing and Interpreting the Q-Sorts

The process for analyzing the Q-Sorts is a factor analysis, whose resulting factors are based on participant viewpoints and capture how similarly individuals sort the statements. It is recommended to follow the process described by Brown [2]. Before the analysis can begin, the Q-Sort for each participant must be recorded and scored based on their placement in the distribution [2]. For example, if a statement were placed in the -2 column, it would receive a score of -2. This scoring is completed for each of the Q-Sorts.

Next, once all the statements are scored for each Q-Sort, a factor analysis is conducted [2] using statistical software such as R, SPSS, or PQMethod, which is specifically designed for Q factor analysis. The factor analysis determines the number of different factors which represent the number of varying viewpoints among the participants. The factor loadings, which is how strongly each person relates to the identified factors or viewpoints, is also calculated and whether the factor loadings are significant. After the factors are determined, the factor scores are calculated for each of the statements in the Q-Set based on the factor loadings [4], [25], which is used to identify which statements were particularly salient for each of the factors. It is interpreted that the participants with similar viewpoints will have similar significant factor loadings for a given factor and will be dissimilar to the other factors or viewpoints.

Once the factor analysis is complete, the results are interpreted using the explanations the participants provided during the follow-up interview for how their experiences impacted their sorting process [2]. First, it is recommended to either transcribe the interviews if they were recorded or write detailed memos for each interview. These transcriptions or notes can be analyzed in mixed methods or qualitative software, such as Dedoose or NVivo. To analyze the

\section{Tip \#6}

Take detailed notes during the interview and note which statement number the participant is discussing. This will make the mixing of the qualitative and quantitative data quicker and easier. 
transcripts or notes of the participants in each respective factor, it is recommended to follow either the consensus or distinguishing card content analysis techniques described by Gallagher and Porock [48] specifically for Q methodology. This analysis supports the explanations for why certain statements are significant for defining the composition of each of the factors. Ultimately, the Q-Sort analysis results in a set of factors that represent the variety of viewpoints of the participants as interpreted by their own subjective experiences and rationale for their rankordering of the statements.

Example Study. The analysis for the example study is currently being performed using R. The researchers selected to use $\mathrm{R}$ based on their familiarity and experience with the software. $\mathrm{R}$ also has a 'qmethod' package that the researchers are using to perform all of the analysis [49]. The researchers also decided to audio-record and transcribe each of the Q-Sort interviews. These transcriptions are being analyzed using Dedoose and following one of the recommended analysis processes, the distinguishing card content analysis. The distinguishing card content analysis searches for the distinguishing items and identifies the rationale provided by participants associated with each factor, which aligns with the purpose of the study. The authors are looking forward to determining the final results.

\section{Recommended Timeline}

To support the design and planning of a Q methodology research study, a recommended 9-month timeline is provided in Table 3 for completing each step, based on the timeline used for the example study.

\section{Table 3: Recommended Timeline for a $Q$ Methodology Study}

\begin{tabular}{|c|c|c|c|c|c|c|c|c|c|}
\hline Step & 胥 & 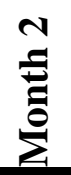 & ${ }_{\sum}^{\infty}$ & $\begin{array}{l}\nabla \\
\stackrel{\Xi}{\Xi} \\
\sum\end{array}$ & 保 & 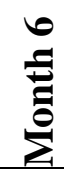 & 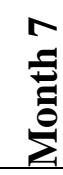 & 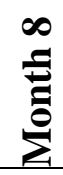 & $\hat{\underline{\Xi}}$ \\
\hline Step 1: Determine Q Concourse & & & & & & & & & \\
\hline Step 2: Develop the Q-Set & & & & & & & & & \\
\hline Determine Initial Q-Set & & & & & & & & & \\
\hline Pilot and Finalize Q-Set & & & & & & & & & \\
\hline Step 3: Select the P-Set & & & & & & & & & \\
\hline Step 4: Conduct the Q-Sort & & & & & & & & & \\
\hline Step 5: Analyze and Interpret Results & & & & & & & & & \\
\hline
\end{tabular}

\section{Conclusion}

Q methodology is a social science research methodology used to study how people think about a topic, defined as their viewpoint, as based on their individual experiences. As a mixed methods research methodology, it combines the strength of qualitative data collection with complex quantitative data analysis. The qualitative data collected is used to interpret and enhance the 
results of the quantitative analysis. While Q methodology is not generalizable, its resulting factors represent generalizations about how people with the same viewpoint think about the topic. Therefore, it is an appropriate methodology to use to explore and understand participants' experiences and viewpoints on a specific topic. Table 4 below shows a summary of the $Q$ methodology steps, components, and "tricks of the trade" learned based on conducting a Q methodology-based research study.

Table 4: Summary of Q Methodology Steps, Components, and Tricks of the Trade

\begin{tabular}{|c|c|c|}
\hline Step & Component & Tricks of the Trade \\
\hline $\begin{array}{l}\text { 1. Determine the } \\
\text { Q Concourse }\end{array}$ & $\begin{array}{l}\text { Q Concourse: the } \\
\text { set of all possible } \\
\text { statements on a } \\
\text { topic }\end{array}$ & $\begin{array}{l}\text { - Perform a review of scientific and/or popular } \\
\text { literature. } \\
\text { - } \text { Interview or observe participants. } \\
\text { organize the Q Concourse and the sources of its } \\
\text { statements. Be sure to track the statements and } \\
\text { their sources. }\end{array}$ \\
\hline $\begin{array}{l}\text { 2. Develop the } \\
\text { Q-Set }\end{array}$ & $\begin{array}{l}\text { Q-Set, a } \\
\text { representative } \\
\text { subset of the Q } \\
\text { Concourse }\end{array}$ & $\begin{array}{l}\text { - Select a "broadly representative" subset of the Q } \\
\text { Concourse. } \\
\text { - Balance the number of statements for each topic } \\
\text { being studied. } \\
\text { - Tip \#2: Pilot the Q-Set iteratively before } \\
\text { finalizing the statements. }\end{array}$ \\
\hline $\begin{array}{l}\text { 3. Select the P- } \\
\text { Set }\end{array}$ & $\begin{array}{l}\text { P-Set, a structured, } \\
\text { non-random set of } \\
\text { participants }\end{array}$ & $\begin{array}{l}\text { - May occur simultaneously as Steps } 1 \text { and } 2 \text {. } \\
\text { - Make sure to have enough participants that } \\
\text { represent the anticipated viewpoints. } \\
\text { - The size of the P-Set should be smaller than the } \\
\text { size of the Q-Set. } \\
\text { Tip \#3: Use stratified purposeful sampling rather } \\
\text { than a random or convenience sample. }\end{array}$ \\
\hline $\begin{array}{l}\text { 4. Conduct the } \\
\text { Q-Sort }\end{array}$ & $\begin{array}{l}\text { Q-Sort, rank- } \\
\text { ordered } \\
\text { distribution of the } \\
\text { Q-Set by the P-Set }\end{array}$ & $\begin{array}{l}\text { - Prepare the materials: sorting cards and } \\
\text { distribution board. } \\
\text { - Decide whether to perform the Q-Sorts in-person } \\
\text { or online. } \\
\text { Tip \#4: Begin the Q-Sort interview with a practice } \\
\text { sort, such as breakfast food items. } \\
\text { - Tip \#5: Provide the participants a sorting board, } \\
\text { such as a poster print-out, to guide the participants } \\
\text { and allow them to sort directly on the board. } \\
\text { - After the sorting process, conduct a follow-up } \\
\text { interview to discuss participants' rationale for } \\
\text { their sorting. } \\
\text { Expect the interview to take } 60 \text { to } 90 \text { minutes. }\end{array}$ \\
\hline
\end{tabular}




\begin{tabular}{|c|c|c|}
\hline Step & Component & Tricks of the Trade \\
\hline $\begin{array}{l}\text { 5. Analyze and } \\
\text { Interpret Results }\end{array}$ & $\begin{array}{l}\text { Q-Sort Factor } \\
\text { Analysis }\end{array}$ & $\begin{array}{l}\text { - Record and score each of the Q-Sorts. } \\
\text { - Perform a factor analysis on the Q-Sort scores. } \\
\text { - Tip \#6: Take detailed notes during the interview } \\
\text { and note which statement number the participant } \\
\text { is discussing. This will make the mixing of the } \\
\text { qualitative and quantitative data quicker and } \\
\text { easier. } \\
\text { - Interpret the resulting factors using the } \\
\text { explanations provided during the follow-up } \\
\text { interviews. } \\
\text { Analyze the follow-up interviews using a card } \\
\text { content analysis technique. }\end{array}$ \\
\hline
\end{tabular}

Q methodology is a useful methodology in engineering education research to explore subjective viewpoints on a topic. Inherently mixed methods, understanding of the results is enhanced by utilizing both qualitative and quantitative research techniques. By raising awareness of and learning new methodologies, such as Q methodology, engineering education researchers will be able to answer new questions, elicit new insights, and expand their skillsets. 


\section{References}

[1] J. W. Creswell, Research design: Qualitative, quantitative and mixed methods approaches, 4th ed. Thousand Oaks, CA: SAGE Publications, Inc., 2014.

[2] S. R. Brown, “A primer on Q methodology,” Operant Subj., vol. 16, no. 3/4, pp. 91-138, 1993.

[3] W. Stephenson, The study of behavior: Q-technique and its methodology. Chicago, IL: University of Chicago Press, 1953.

[4] I. Newman and S. Ramlo, "Using Q methodology and Q factor analysis in mixed methods research," in SAGE Handbook of Mixed Methods in Social \& Behavioral Research, 2nd ed., A. Tashakkori and C. Teddlie, Eds. Thousand Oaks, CA: SAGE Publications, Inc., 2010, pp. 505-530.

[5] B. McKeown and D. B. Thomas, $Q$ Methodology, 2nd ed. Thousand Oaks, CA: SAGE Publications, Inc., 2013.

[6] R. Stainton Rogers, "Q methodology," in Rethinking Methods in Psychology, J. A. Smith, R. Harre, and L. Van Langenhove, Eds. London, UK: SAGE Publications, 1995.

[7] R. L. Kajfez, C. M. Croyle, A. N. Snyder, and M. J. Mohammadi-Aragh, "Engineering education Ph.D. Students: Where are they now and what was the job search process like?," ASEE Annu. Conf. Expo., 2014.

[8] Y.-L. Liu, H.-P. Yueh, T.-L. Chen, and H.-J. Sheen, "Identifying nanotechnology professional competencies for engineering students using Q methodology," Int. J. Eng. Educ., vol. 31, no. 5, pp. 1389-1397, 2015.

[9] C.-C. Chang, "Obtaining IT competencies for curricular development using Q-technique," Int. J. Acad. Res. Bus. Soc. Sci., vol. 4, no. 3, 2014.

[10] D. A. Haworth and F. J. Van Wetering, "Determining underlying corporate viewpoints on information systems education curricula," J. Educ. Bus., vol. 69, no. 5, pp. 292-295, 2010.

[11] S. E. Ramlo, "Q methodology as a tool for program assessment.," Mid-Western Educ. Res., vol. 27, no. 3, pp. 207-223, 2015.

[12] D. Simmons, C. Tendhar, R. Yu, E. Vance, and C. Amelink, "Developing the postsecondary student engagement survey (PosSES) to measure undergraduate engineering students' out-of-class involvement," in 11nd ASEE Annual Conference \& Exposition, 2015.

[13] S. A. Woosley, R. E. Hyman, and S. S. Graunke, "Q sort and student affairs: A viable partnership?," J. Coll. Stud. Dev., vol. 45, no. 2, pp. 231-242, 2007.

[14] C. M. Ray and D. M. Montgomery, "Views in higher education toward methods and approaches for character development of college students," J. Coll. Character, vol. 7, no. 
$5,2010$.

[15] S. Speight, N. Lackovic, and L. Cooker, "The contested curriculum: Academic learning and employability in higher education," Tert. Educ. Manag., vol. 19, no. 2, pp. 112-126, 2013.

[16] T. J. Kopcha, L. P. Rieber, and B. B. Walker, "Understanding university faculty perceptions about innovation in teaching and technology," Br. J. Educ. Technol., vol. 47, no. 5, pp. 945-957, 2016.

[17] D. L. Oswald and R. D. Harvey, "A Q-methodological study of women's subjective perspectives on mathematics," Sex Roles, vol. 49, no. 3/4, pp. 133-142, 2003.

[18] S. E. Ramlo, "Determining the various perspectives and consensus within a classroom using Q methodology," AIP Conf. Proc., vol. 1064, no. October, pp. 179-182, 2008.

[19] R. T. Hall, R. R. Jensen, and D. D. McLean, "Learning in the geoscience classroom: Qmethodology, learning styles, and individual preferences," J. Geosci. Educ., vol. 61, no. 1, pp. 120-128, 2013.

[20] S. E. Ramlo, "Students' views about potentially offering physics courses online," J. Sci. Educ. Technol., vol. 25, no. 3, pp. 489-496, 2016.

[21] W. Stephenson, "Factors as operant subjectivity," Operant Subj., vol. 1, no. 1, pp. 3-16, 1977.

[22] W. Stephenson, "Introduction to Q-Methodology," Operant Subj., vol. 17, no. 1/2, pp. 113, 1994.

[23] S. R. Brown, "Q methodology," in The SAGE Encyclopedia of Qualitative Research Methods, L. M. Given, Ed. Thousand Oaks, CA: SAGE Publications, Inc., 2008, pp. 69902 .

[24] W. Stephenson, "Protoconcursus: The concourse theory of communication," Operant Subj., vol. 9, no. 2, pp. 37-58, 1986.

[25] S. R. Brown, Political subjectivity: Applications of $Q$ methodology in political science. Yale University Press, 1980.

[26] J. van Exel and G. de Graaf, "Q methodology: A sneak preview," 2005.

[27] S. Watts and P. Stenner, "Doing Q methodology: Theory, method and interpretation," Qual. Res. Psychol., vol. 2, no. 1, pp. 67-91, 2005.

[28] J. M. Case and G. Light, "Emerging methodologies in engineering education research," $J$. Eng. Educ., vol. 100, no. 1, pp. 186-201, 2011.

[29] M. Brouwer, "Validity: Q vs. R," Operant Subj., vol. 16, no. 1/2, pp. 18-36, 1992. 
[30] D. B. Thomas and L. R. Baas, "The issue of generalization in Q methodology: 'Reliable schematics' revisited," Operant Subj., vol. 16, no. 1/2, pp. 18-36, 1992.

[31] D. Kahneman and A. Tversky, "The simulation heuristic," in Judgment under uncertainty: Heuristics and biases, D. Kahneman, P. Slovic, and A. Tversky, Eds. New York, NY: Cambridge University Press, 1982, pp. 201-208.

[32] M. London, "Toward a theory of career motivation," Acad. Manag. Rev., vol. 8, no. 4, pp. 620-630, 1983.

[33] D. R. Anderson, "Female executives in biotechnology: A contextual approach to understanding their work environments," Operant Subj., vol. 28, no. 1/2, pp. 33-57, 2004.

[34] B. P. Godor, "Moving beyond the deep and surface dichotomy; using Q Methodology to explore students' approaches to studying," Teach. High. Educ., vol. 21, no. 2, pp. 207218, 2016.

[35] M. S. Rye, M. B. Cahoon, R. S. Ali, and T. Daftary, "Development and validation of the counterfactual thinking for negative events scale," J. Pers. Assess., vol. 90, no. 3, pp. 261$269,2008$.

[36] R. Day and T. D. Allen, "The relationship between career motivation and self-efficacy with protégé career success," J. Vocat. Behav., vol. 64, no. 1, pp. 72-91, 2004.

[37] J. J. VanAntwerp and D. Wilson, "Difference between engineering men and women: How and why they choose what they do during early career," in 2015 ASEE Annual Conference and Exposition, 2015.

[38] N. A. Fouad, R. Singh, K. Cappaert, W. Chang, and M. Wan, "Comparison of women engineers who persist in or depart from engineering," J. Vocat. Behav., vol. 92, pp. 79-93, 2016.

[39] M. Brouwer, "Q is accounting for tastes," J. Advert. Res., vol. 39, no. 2, pp. 35-39, 1999.

[40] G. W. K. Ho, "Examining perceptions and attitudes: A review of likert-type scales versus Q-methodology," West. J. Nurs. Res., vol. 39, no. 5, pp. 674-689, 2017.

[41] M. Sandelowski, "Combining qualitative and quantitative sampling, data collection, and analysis techniques in mixed-method studies," Res. Nurs. Health, vol. 23, no. 3, pp. 246255, Jun. 2000.

[42] C. Teddlie and F. Yu, "Mixed methods sampling: A typology with examples," J. Mix. Methods Res., vol. 1, no. 1, pp. 77-100, Jan. 2007.

[43] A. J. Onwuegbuzie and K. M. T. Collins, "A typology of mixed methods sampling designs in social science research," Qual. Rep., vol. 12, no. 2, pp. 281-316, 2007.

[44] M. Dairon, S. Clare, and J. R. Parkins, "Participant engagement and data reliability with 
internet-based Q methodology: A cautionary tale," Operant Subj., vol. 39, no. 3/4, pp. 4659, 2017.

[45] C. Davis and C. Michelle, "Q methodology in audience research: Bridging the qualitative/quantitative 'divide," Particip. J. Audience Recept. Stud., vol. 8, no. 2, pp. 559-593, 2011.

[46] QMethod Software, "Q method software," 2020. [Online]. Available: https://qmethodsoftware.com/.

[47] F. Dziopa and K. Ahern, "A systematic literature review of the applications of Qtechnique and its methodology," Methodology, vol. 7, no. 2, pp. 39-55, 2011.

[48] K. Gallagher and D. Porock, "The use of interviews in Q methodology," Nurs. Res., vol. 59, no. 4, pp. 295-300, 2010.

[49] A. Zabala and M. Held, "Analysis of subjective perspectives using Q methodology," 2018. 